\title{
Evaluation of Satellite Imagery to Increase Crop Yield in Irrigated Agriculture
}

\author{
Michael Hoffmann', Yaryna Butenko', Seydou Traore ${ }^{2}$ \\ ${ }^{1}$ Institute of Water Problems and Land Reclamation, Kiev, Ukraine \\ ${ }^{2}$ Department of Biological \& Agricultural Engineering, Texas A\&M University
}

\begin{abstract}
The main aim of this study was to work out a satellite-imagery based approach that can be used to improve agricultural crop growing on a bigger-scale and on field level. Instead of working on small experimental fields, various vast farms have been selected, which were ready to cooperate for this study. Especially for the dry south of Ukraine, vegetation and soil indices provide useful information to improve crop development and productivity. However, many index variants produce similar results or unclear structures; therefore, their information content is restricted under practical conditions. The results analysis shows that a few indices are sufficient to regularly monitor irrigated fields. Talks with farmers revealed that advice is mainly needed to secure crop growth, leading to the decision to firstly select the indices NDVI and/or EVI. To detect failures in an early stage, we additionally used DIRT, NDRE, LAI, NMDI and OSAVI. NMDI could also be used to monitor irrigation activities. This article provides examples illuminating the implemented methodology.
\end{abstract}

\section{Keywords}

Remote sensing (RS), NDVI, vegetation index, irregular crop growth, satellite imagery, irrigation

Hoffmann, M., Butenko, Y. and Traore, S. (2018) "Evaluation of Satellite Imagery to Increase Crop Yield in Irrigated Agriculture", AGRIS on-line Papers in Economics and Informatics, Vol. 10, No. 3, pp. 45-55. ISSN 1804-1930. DOI 10.7160/aol.2018.100304.

\section{Introduction}

Satellite imagery is increasingly used to optimize agricultural production (De Solan et al., 2012). Since the launch of the first Landsat satellite in 1972, agricultural monitoring has been implemented and improved worldwide (USGS, 2017). The aim of those activities was related to providing information on global or countrywide crop production, agricultural water use (irrigation), state statistic services and so far. On a smaller scale, satellite imagery was used for consulting of private farmers. Benedetti and Rossini (1993) selected NDVI and a regression model to predict best crop yield while other authors preferred PVI in combination with a Neural Network model for crop yield forecast (Panda et al., 2010).

The focus of this paper was not only on monitoring of crop growth but also the determination and optimization of some influential factors on field level while providing an overview on big agricultural areas. In our investigation area, located in south Ukraine, the number of fields and maximal distances between them (up to $156 \mathrm{~km}$ straight line) were too big for regular field monitoring. This is however important as climatic conditions (Weather Online, 2017; FAO, 2017) require the application of irrigation (Frenken and Gillet, 2012; Bastiaanssen et al., 2000) and appropriate investments in its infrastructure and energy consumption (Duran et al., 2014). Facing a big number of different crops, as well as various types of available satellite imagery and modeling software, it becomes challenging to think of the best management approach while taking into account farmers requirements (De Solan et al., 2012). The data flow has to be quick and frequent enough to support precision agriculture and, as far as possible, irrigation management. We therefore used three different satellites facing the disadvantage that the singular bands' radiation spectra and resolutions are not identical (Congedo 2016), but fortunately results of index calculation differ only slightly (Mandanici and Bitelli, 2016). Because of the big distances between the fields, the images covered only smaller parts of the study area at different times. In addition, soil and weather 
conditions were often different, even if fields were not far from each other, like a few hundred meters.

The objective of this work was to assess various vegetation indices, besides the commonly used Normalized Difference Vegetation Index (NDVI), to clarify reasons of reduced or uneven growth as can be caused for example by weeds, and, if possible, to take countermeasures. It was preferable to provide such information visually and/or enable calculation and assessment of boundary conditions that might be necessary to be changed to optimize crop growth. Results must be applicable in spite of strong differences between the most important crop types in terms of sowing date, growth forms, growth speed and state before harvest. We therefore put efforts on answering those questions as far as possible and provide advices for future improvements, determine irrigation need and, eventually, expected crop yield.

Taking into account all these circumstances, the challenge was to get as much as possible information out of the combined use of satellite imagery even under unfavorable preconditions, to detect and overcome the shortcomings and to use it for applied agricultural purposes. Last, not least, consulting costs-performance ratio had to be attractive for farmers with respect to the overall agricultural profitability.

\section{Materials and methods}

\section{Study area and investigation period}

In this study, the research team closely cooperated with individual growers and technical staff of large farms. Five farms were chosen for the study with more than 240 fields and a size per field of 50-100 ha in the region of Kherson and Zaporizhia Oblast (province) in south Ukraine (Figure 1). They are largely flat, only a few fields are uneven showing heights differences (depressions) of up to $4 \mathrm{~m}$. The climate is rather dry with precipitations of 300-450 mm per year and often-violent thunderstorms in summer (FAO, 2017).

Imagery conversion and evaluations were performed occasionally in 2013, monthly in 2016 and 2017 during the winter months and as often as possible, about three to five times per month, during the vegetation period.

\section{Data sources}

In order to reduce costs, only free of charge satellite imagery was used. The selected satellites were Landsat 8 OLI/TIRS (further abbreviated Ls8), in a few cases Landsat7 ETM+ (Ls7) and the European satellite Sentinel 2a (S2a). The sensors, carried by these satellites, are described in (NASA and USGS, 2017; ESA, 2017;

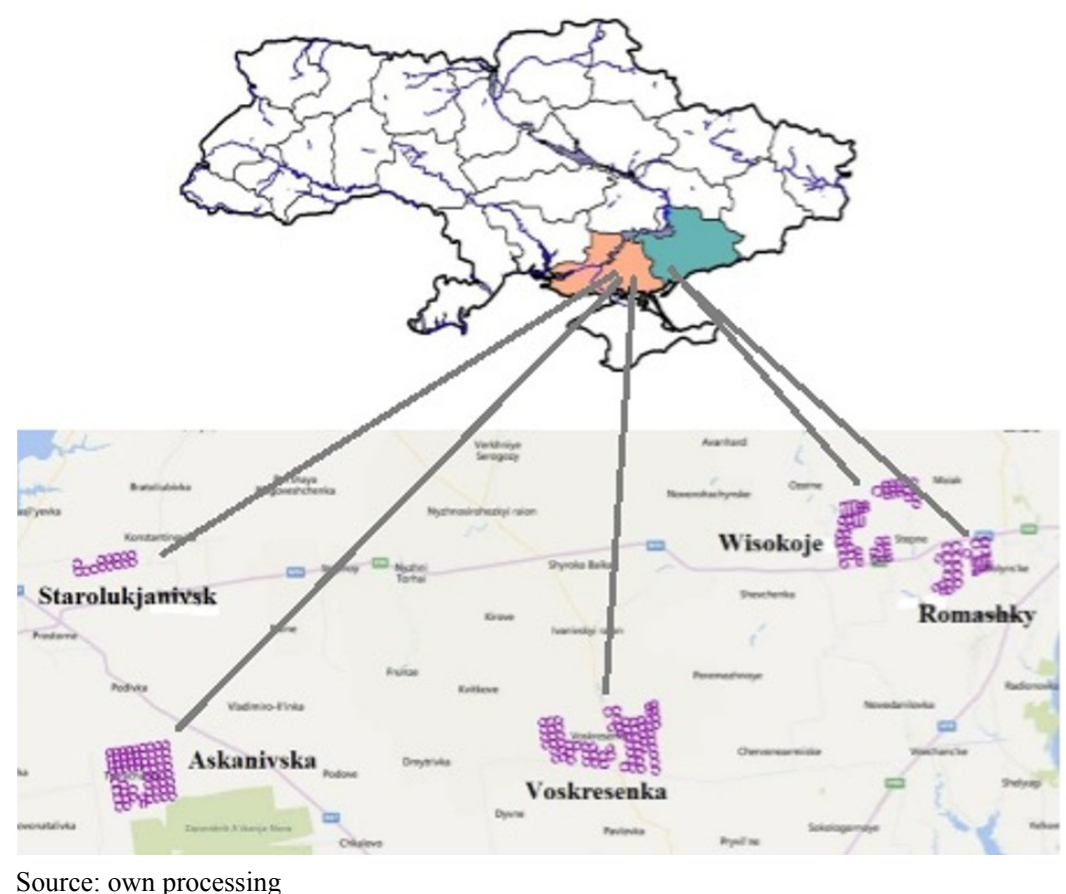

Figure 1. Location of farms in south Ukraine; distance Askanivska - Romashky straight line about $150 \mathrm{~km}$. 
Wang et al., 2017). The images are composed of series of bands covering defined sections of the visible and infra-red electromagnetic spectrum of solar radiation; they are available with sufficient resolution (Ls8: 30 and $100 \mathrm{~m}$ per pixel; S2a: 10, 20 and $60 \mathrm{~m}$ ) depending on the layer (band number). Further details about selection and download are available on several websites (USGS, 2017). For selection and download, the open source software (QGIS v. 2.18.15) together with the plugin "Semi-automatic Classification Plugin" (SCP, version 5.3.10) (Congedo, 2017) was used. For technical reasons since May 2017, Ls8 images could only be downloaded from the Earthexplorer website (USGS websites, 2017). Since September 2017, Landsat Surface Reflectance High Level Data Products were additionally available on demand including a selection of seven spectral indices and temperature; (for details see ESPA, 2017). To detect topographical unevenness Google Earth Pro, version 7.3.0.3832 was used first, and besides, results of the Shuttle Radar Topographic Mission (SRTM) (CGIAR-CSI, 2017) to prepare a digital elevation model (DEM) and calculate possible ditch courses using the modeling software AVSWATx (Arnold et al. 1998).

\section{Data pre-processing}

In addition to the SCP, a second QGIS plugin, "RS\&GIS-17", version 0.4 (Barane and Dwarakish, 2017) was used for data processing. Both plugins support various file types of satellite bands, clipping to smaller areas and their conversion from DN files to radiance and top of atmosphere reflectance being required to calculate spectral indices, albedo and temperature. For atmospheric correction, SCP uses the Dark Object Subtraction 1 (DOS 1) method (Chavez, 1996). When clouds and/or their shadows were visible, they have been masked with the QGIS plugin Cloud Masking (Corredor-Llano, 2017) and excluded from statistical raster calculation. Fields, covered by clouds and/or cloud shadows by more than about half, have been completely removed from the analysis. RS\&GIS-17 can use compressed Landsat files as provided for download and provides the possibility to account for clouds and cirrus. Results obtained when using the two plugins and the high level data products differ only slightly but it is not necessary to consider them in practice when comparing results, as other impacts can play a much bigger role. (For more detailed comparative studies, see Mandanici and Bitelli, 2016; Congedo, 2016). In addition, ENVI, software version 5.4, was occasionally used for in-depth analysis of scatter plots.

For our study, NDVI has always been calculated first as main index for comparison of crop fields. Thereafter, a broader spectrum of indices was selected to test their usefulness with respect to quite different crop types and growth problems, and to enhance interpretation of results:

\section{- Difference Index with Red Threshold (DIRT) \\ - Enhanced Vegetation Index (EVI) \\ - $\quad$ Leaf Area Index (LAI) \\ - Normalized Multi-band Drought Index (NMDI) \\ - Normalized Difference Red Edge Index (NDRE) \\ - Optimized Soil Adjusted Vegetation Index (OSAVI)}

These indices are not further described here because a big number of related publications is already available. Indices, selected for in-depth studies, and used calculation methods are listed in the Table 1 . Results are visualized as colored raster, but for further assessments and comparisons, statisticalparametersforeachsingularfieldandculture were additionally calculated. In many cases, the various pixel values are not evenly and not normally distributed within singular fields and accordingly non-parametric statistics had to be applied. For our work, the 50-percentile (median) has been calculated (using QGIS zonal statistics) and the Spearman rank correlation coefficient to determine the relation between various indices. The interrelation between indices was visualized as scatterplots using the QGIS plugin Raster Best_Fit_Scatterplot (Brom, 2015), ENVI v.5.4 and the MS windows program Statistica 8.

\section{Results and discussion}

\section{Visualization of irregular crop growth}

The prevalent vegetation index NDVI was regularly determined using Ls8, Ls7 and S2a imagery. For the diagram (Figure 2), four obviously well growing maize fields, located in the Askanivska complex, were selected; unusable image sections (fields) with clouds or cloud shadows were masked out and only typical time series curves were obtained. 


\begin{tabular}{|c|c|c|}
\hline Index & Formula & Reference \\
\hline DIRT & $\begin{array}{l}\text { np. } \operatorname{sign}(\beta-\text { band } 4) *(\text { band } 5-\text { band } 4) /(\text { band } 5+\text { band } 4) \quad\{\beta=0.12\} \\
\{\text { bands provided by Landsat } 8 \text { OLI/TIRS }\}\end{array}$ & Langner et al., 2016 \\
\hline EVI & $\begin{array}{l}\text { band } 3 *(\text { band } 5-\text { band } 4) /(\text { band } 5+\mathrm{C} 1 * \text { band } 4-\mathrm{C} 2 * \text { band } 2+\mathrm{L}) \\
\{\mathrm{C} 1=6.0 ; \mathrm{C} 2=7.5 ; \mathrm{L}=1\} \\
\{\text { bands provided by Landsat } 8 \text { OLI/TIRS }\}\end{array}$ & Matsushita et al., 2007 \\
\hline LAI & 3.618*EVI- 0.118 & Goswami et al., 2015 \\
\hline NDVI & $\begin{array}{l}(\text { band5-band } 4) /(\text { band } 5+\text { band } 4) \\
\{\text { bands provided by Landsat } 8 \text { OLI/TIRS }\end{array}$ & Meera Gandhi et al., 2015 \\
\hline NMDI & $\begin{array}{l}\text { band } 8 \mathrm{~A}-(\text { band } 11-\text { band } 12) / \text { band } 8 \mathrm{~A}+(\text { band } 11-\text { rband } 12) \\
\{\text { bands provided by Sentinel } 2 a\}\end{array}$ & Wang and Qu, 2007 \\
\hline NDRE & $\begin{array}{l}(\text { band } 8-\text { band } 6) /(\text { band } 8+\text { band } 6) \\
\{\text { bands provided by Sentinel } 2 a\}\end{array}$ & Tilling et al., 2007 \\
\hline OSAVI & $\begin{array}{l}1.16 *(\text { band } 5-\text { band } 4) /(\text { band } 5+\text { band } 4+0.16) \\
\{\text { bands provided by Landsat } 8 \text { OLI/TIRS }\}\end{array}$ & Rondeaux et al., 1996 \\
\hline
\end{tabular}

Source: own processing

Table 1. List of used indices and band calculation formulas; abbreviations: B - blue, G - green, R - red, NIR - near-infrared.

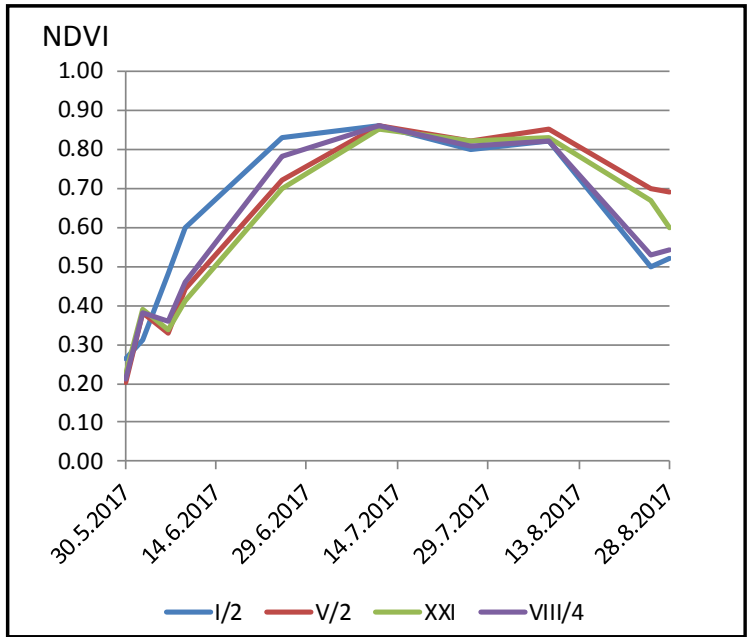

Source: own processing

Figure 2: Result of NDVI monitoring (50-percentiles) of four maize fields, days of irrigation excluded.

As monitoring showed, NDVI pixels are not evenly distributed over the farm fields because of manmade influences and also natural irregularities. This implies technical and irrigation management problems on the one hand and variability of soil quality, weather conditions, topography etc. on the other. The detection of problems on the huge farm areas using satellite imagery is quick and favorable and can have an advantage for better crop yields as shown in figures 3-5, illustrated herein as typical examples.

In figure 3, we found that irregular growth was due to a lack of optimal operation of a Fregat sprinkler machine (Fregat, 2018) on soy fields in the Wisokoje complex. As can be seen, the water distribution was partly defective or at least inadequate. To assess these irregularities, singular pixel values have been identified for further analysis. The sprinkler machine was controlled and had to be repaired.

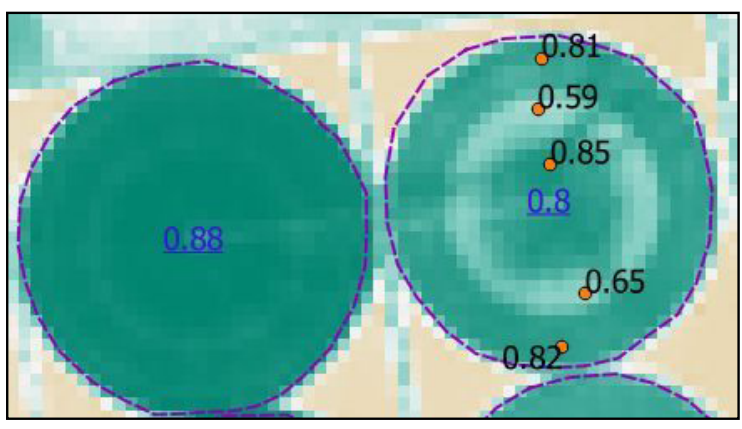

Source: own processing

Figure 3: Soy fields with indication of the 50-percentil of NDVI in blue, (Ls8 imagery from August 9, 2016); a) regular crop growth, b): irregular growth; figures indicate singular NDVI pixel values.

Figure 4 shows growth differences caused by topographical unevenness on a field of the Wiskoje complex, (a) shown with Google Earth Pro, and (b), by using a DEM based on SRTM data. According to Fournier (1967), cited in Roose, (1996) rain can cause erosion even on gentle slopes (like 2\%). Moreover, soil characteristics are changed and crop growth altered. In our study (also Wiskoje, in 2017), we found ditches with bank slopes up to $4 \%$; they drain neighboring fields and can change their productivity. The yields (weights) of soybean grains on two fields neighboring such a ditch were $6 \%$ resp. $11 \%$ higher than on the two higher adjacent fields.

Another, more frequent problem is the growth of weeds or other irregularities as visible on Figure 5. For this purpose, Langner et al. (2016) have proposed to calculate DIRT that should indicate the dispersion of weed on mulched fields.

Besides, the various types of crop growth 

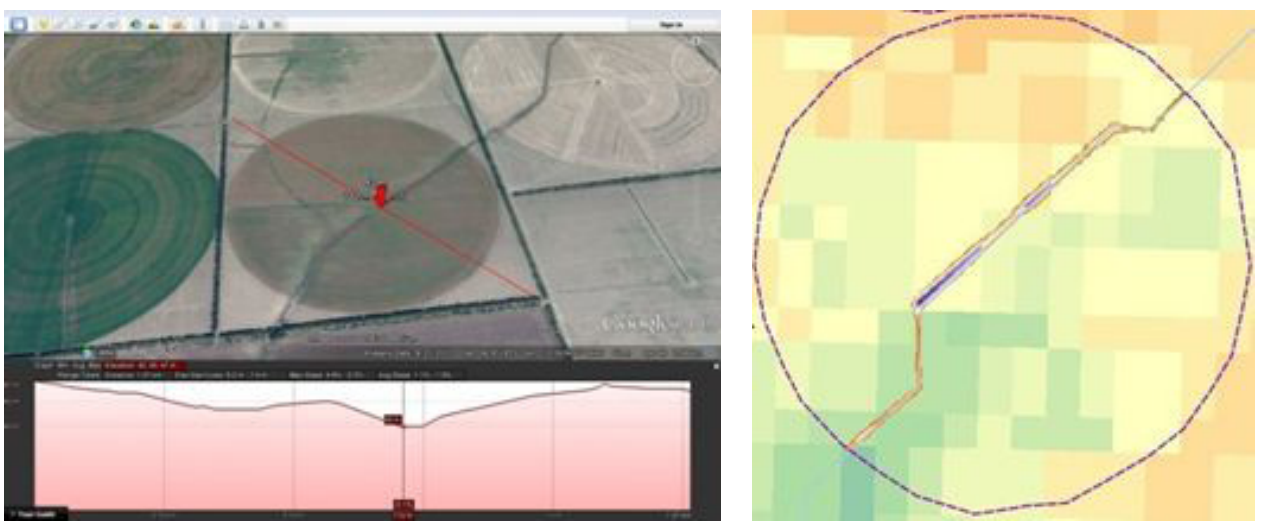

Source: own processing

Figure 4: Irregular crop growth caused by erosion in the field; a): visualization of an overgrown water ditch, (top view and cross-section by Google Earth); b): DEM (pixel size 90m) of the same field and ditch course.
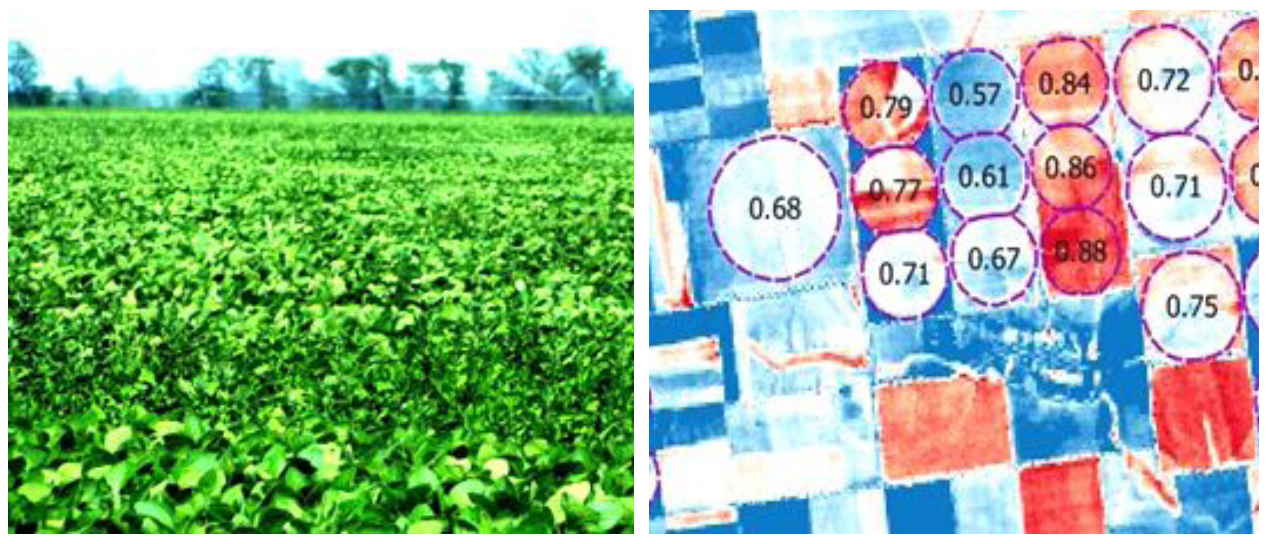

Source: own processing

Figure 5: Unidentified irregularities as shown by a photo (a) and by DIRT (b), Ls8 imagery, June 9, 2017; Wisokoje.

and crop-similar weeds can cause uncertainties. Therefore, the results are considered only as hint on a noticeable deviation from vegetative growth standard (less clearly shown by NDVI). However, in modern agriculture weed is mostly suppressed by herbicides. For regular monitoring and reliable interpretation DIRT maps require additional experts' surveying on-site.

Another reason for growth irregularities appears when chemicals are distributed unevenly on the field. Figure 6a shows green-yellow stripes across a maize field; they appeared on the Starolukianivka complex in August 2017. Figure 6b and 6c show S2a images, used for NDVI and NDRE calculation, one day earlier.

As can be seen, the NDRE raster (Figure 6c) is significantly more suitable than the NDVI raster (Figure 6b) to detect these anomalies in spite of the fact that the scatterplot (Figure 6d) shows a good correlation between the two indices.
The reasons for the yellow stripes can be manifold and require analyses that are more detailed. A first field visit did not give any hints on parasite effects. In comparison with unaffected plants, affected ones showed brightening and growth impairment. In many cases, a deficit of certain plant nutrients because of uneven distribution of azote or other fertilizers can cause yellowing and growth reduction, as more precisely documented in special manuals as for example in the "Corn Diagnostic Guide" (Iowa State University, 2017). The so far shown imagery demonstrates that various typical agricultural shortcomings can be detected providing the opportunity for taking countermeasures. 

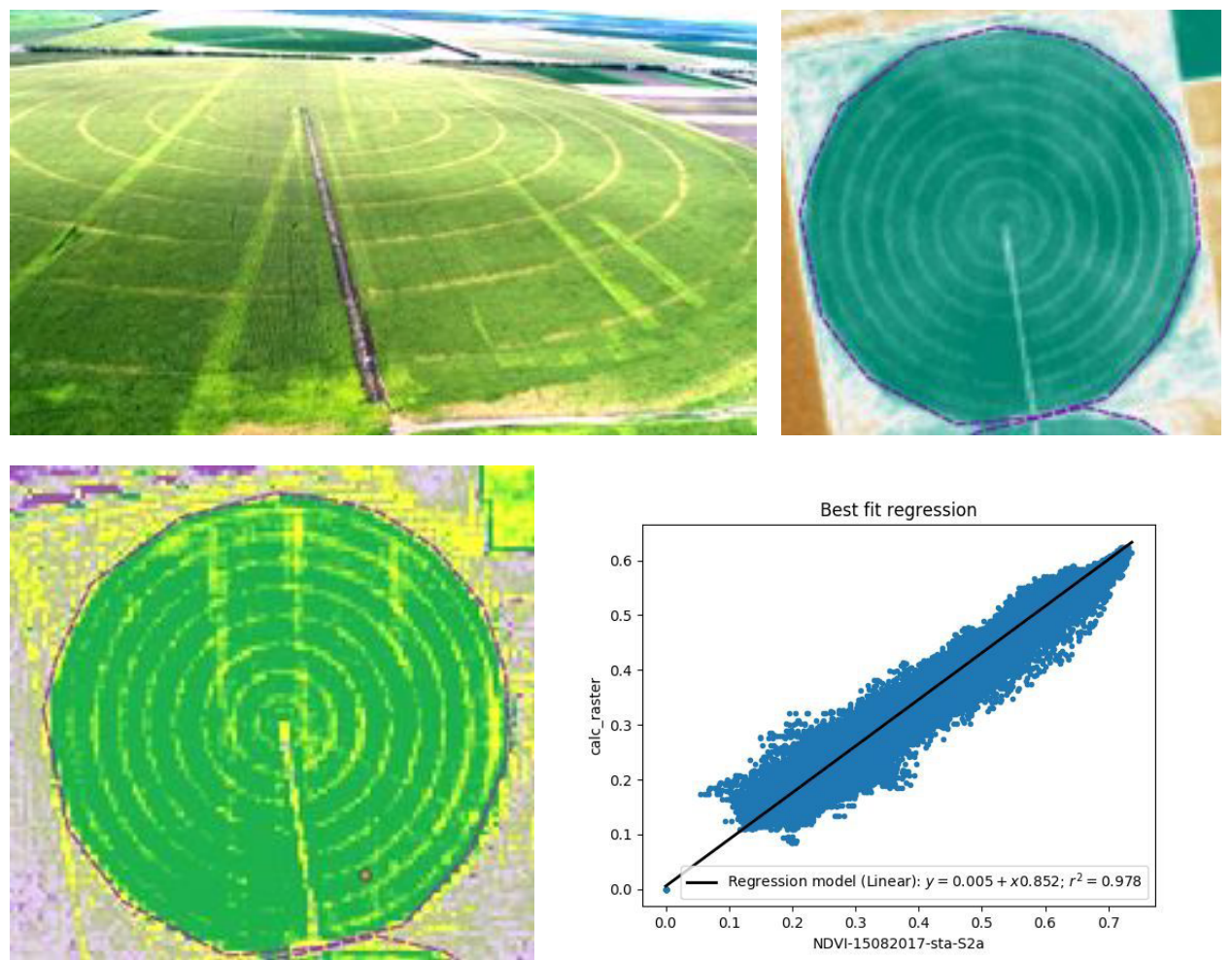

Source: own processing ( a) Photography taken from helicopter (on August 15, 2017, Starolukjanivka),

b) NDVI), c) NDRE, yellow color showing growth reduction, d) d) NDRE(y)-NDVI(x) scatterplot (print screen)

Figure 6. a) Growth disturbance as seen from helicopter, b) and c) NDVI raster and NDRE raster of the same field one day earlier, (d) NDRE - NDVI scatterplot, (based on b) and c)).

\section{Rough assessments of soil moisture and crop yield}

The following evaluations have provided additional insights being relevant for agricultural consulting. At the beginning of the vegetation period, uncovered soil and vegetation are mixed and NDVI allows only a semi-quantitative assessment. Later in the year, depending on the crop type, NDVI reaches a saturation plateau (at values $>0.6$ ) and can lead to an underestimation of biomass and possible yield ( $\mathrm{Gu}$ et al., 2013). Various different alternative indices have been described in the literature to overcome this disadvantage: a. o. ENDVI (Sentek Systems, 2015), OSAVI (Rondeaux et al., 1996), PVI (Bannari et al., 1995), SAVI (Huete, 1988), RDVI (Roujean and Breon, 1995); but the suitability of those indices depends very much on the crop type, growth state, soil cover degree and other parameters that can change from field to field. We therefore also tested and finally preferred the OSAVI and determined NDVI, ( $\mathrm{n}=15$ in 2016, $\mathrm{n}=11$ in 2017,) in parallel as shown in figure 7 . In the range of OSAVI medians between 0.6 and 0.7, crop growth assessment must take into account an underestimate of NDVI by about 0.2 for a mixture of different fields (Wisokoje complex between May 25 and August 12, 2017).

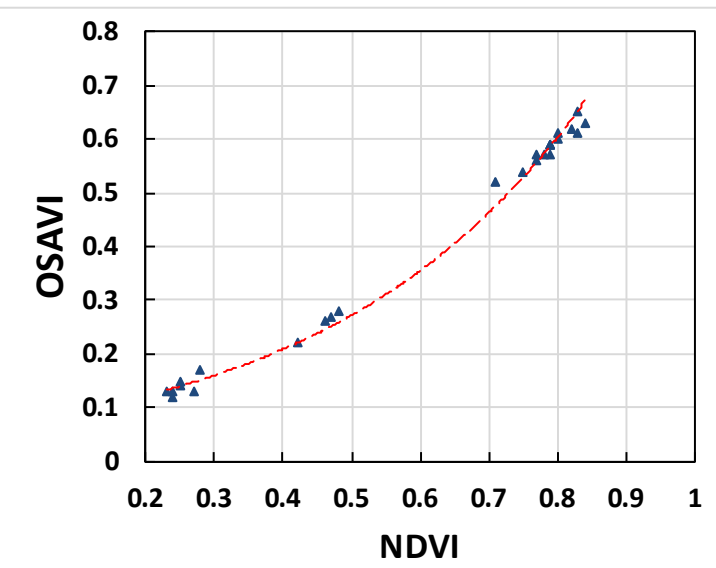

Source: own processing

Figure 7. Relation between 50-percentils of OSAVI and NDVI for various crop fields.

As crop growth is strongly dependent on soil moisture we also made attempts to asses this impact calculating moisture indices such as MI (DupignyGiroux and Lewis, 1999), NMI (Pandolfo 
et al., 2017), NDMI (IDB, 2017), SMI (Hogg et al., 2013; Potić et al., 2017), MSI (IDB, 2017) and WDI (Sánchez et al., 2016). However, in case of dense crop growth, the result is, above all, related to moisture contained in the leaf internal structures. Soil moisture in the root zone or at least on the soil surface is not or not sufficiently indicated e.g. to support decision making for irrigation management; instead, special sensors can better determine it in situ. As replacement solution, the NMDI was additionally tested. It shows notably dry condition for vegetation when pixel values are $<0.6$ and notably dry condition of bare soils with pixels $>0.75$, while intermediate pixel values appear to be less meaningful (Wang and QU, 2007). Figure 8a shows a NMDI map as of May 24, 2017, located in the Wisokoje complex at the beginning of the irrigation period. The dark blue triangles show the start of sprinkler irrigation. Strong droughts are not usual at this time of the year, and during the vegetation period, droughts are combatted in time by applying irrigation. Figure $8 \mathrm{~b}$ shows the relation of NDVI and NMDI in the form of a scatterplot where dark blue pixels are related to the blue pixels in the NMDI raster. Following, one can resume that NMDI, under certain conditions (as mentioned earlier), can indicate strong drought, but can also be useful to supervise the irrigation progress.

Besides soil moisture, farmers are especially interested in expected harvest of different cultures e.g. in terms of biomass. RS imagery can only provide vegetation indices like NDVI or EVI that correlate with the "Leaf Area Index" (LAI) (Wang et al., 2005). As shown in Figure 9, this relation is strongly influenced by the growth form of different crop cultures.
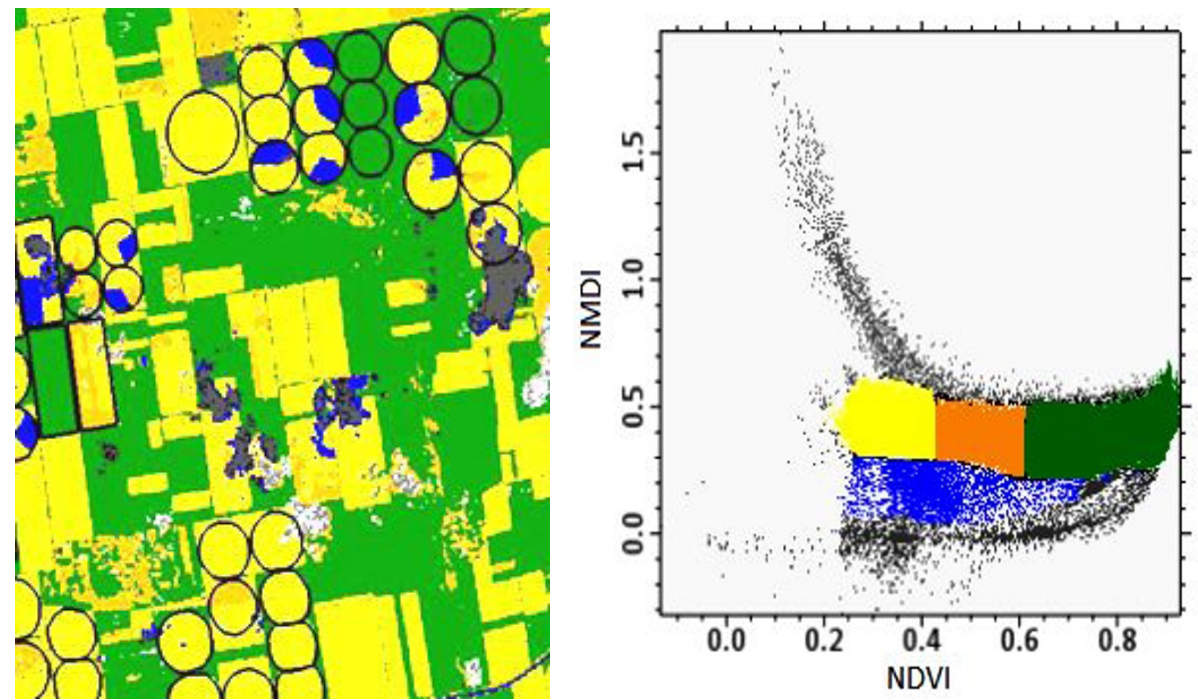

Source: own processing

Figure 8. a) Example of a NMDI raster; green -winter wheat, yellow and brown -soy and partly weed at different early growth stages b) NMDI-NDVI scatterplot; grey and black colors show cloud and cloud shadow pixels, blue irrigated sectors as visible in a).

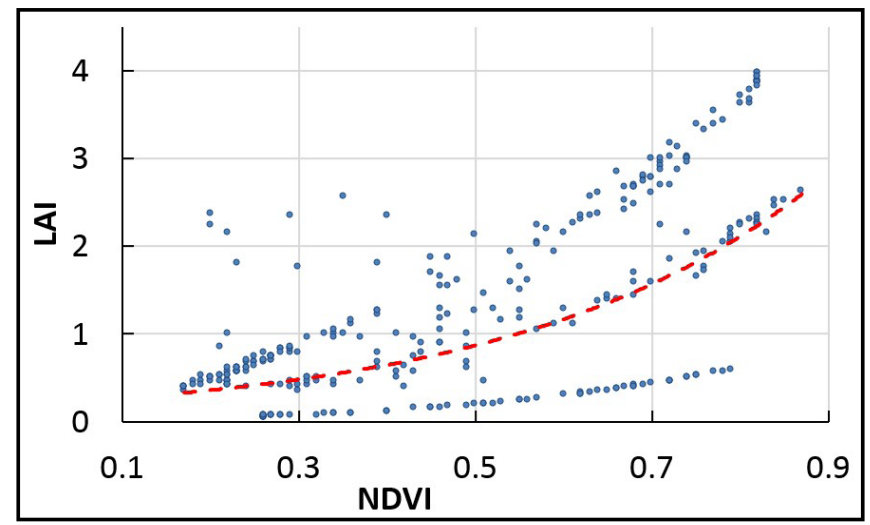

Source: own processing

Figure 9. LAI-NDVI regression (50-percentils of different crops, near Wisokoje), Sept. 9, 2013. 
According to Goswami et al. (2015), the magnitude of biomass can then be assessed by the formula

$$
\text { Biomass }=38.6 * \mathrm{LAI}-\mathbf{2 1 . 2}
$$

Based on these results, the question was posed if merely NDVI can provide a rough hint on the expected harvest of singular crops as was reported earlier by Benedetti and Rossini (1993). As an example, we selected the weight of soybean grains (not the total plant biomass) that the Wisokoje farm harvested in 2017 from 34 different fields. The NDVI medians were analyzed at the time of maximal crop growth (July 2017), then averaged and compared with the soybean weights. The average grain yield (in tons/ha) showed up to correlate well with the maximal NDVI median averages $\left(r^{2}=0.88 ; p=0.05 ; n=34\right)$. These first results, as shown in figure 10, show this rough relationship but the investigation needs to be continued to get more specific input data for various cultures and evaluations in the future.

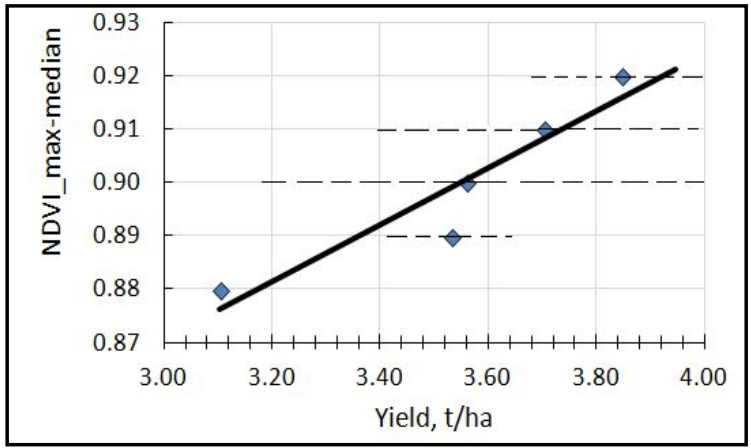

Source: own processing

Figure 9. LAI-NDVI regression (50-percentils of different crops, near Wisokoje), Sept. 9, 2013.

\section{Conclusion}

The work described here is mainly practice oriented, thought to help making daily fieldwork more efficient and increase agricultural productivity in cooperation with big farms. As to our knowledge, such an approach was not reported before

\section{Corrsponding authors}

Dr. rer. nat. Michael Hoffmann

Institute of Water Problems and Land Reclamation

Vasylkivska Street 37, 03022 Kiev, Ukraine

Phone: +380989558916,E-mail:Mi-Hoffmann@gmx.net in Ukraine. The challenge was to include vast field complexes being under different growth conditions. When firstly monitoring NDVI, irregular or unclear structures became quite often visible. Possible reasons could be limited by mapping several other vegetation indices and thus, improved crop growth could be achieved. For this purpose, vegetation index medians were calculated to assess crop growth more accurately for each singular field and to ease comparisons between fields. In case of uneven or insufficient crop growth, further indices were used, e. g. to reduce the influence of uncovered soil on the map (OSAVI), puddles or excess moisture (NMDI). Terrain unevenness, leading to water accumulation and humidity, were simply shown by a DEM and slope calculations (Google Earth). Further disturbances appeared when fertilizers were distributed unevenly. Thereupon, crop growth was impaired, best visible on a NDRE raster.

Farmers' request on potential crop yields was answered approximately and, for the time being, only for expected soybean yields. Our results have shown that a rough estimation of the grain weights is possible when taking into account the mean NDVI-medians at the time of maximal crop growth. During the vegetation period, satellite imagery was not used to calculate the evaporation balance as needed for irrigation planning; instead, we created a new irrigation model ("GIS-Poliv", 2018), but this will be validated only in further research and was therefore not reported here.

\section{Acknowledgments}

The authors want to thank the United State Department of Agriculture, Borlaug International Agricultural Science and Technology Fellowship Program and Texas A\&M University for providing funds for personnel training and purchasing of software used for the work in this article. For consultation and technical supports, we are grateful to all our colleagues of the division Sustainable development and use of reclaimed territories, especially to the head of division Dr. Olga Zhovtonog. 


\section{References}

[1] Arnold, J. G., Srinivasan, R., Muttiah, R. S. and Williams, J. R. (1998) "Large area hydrologic modelling and assessment, part I: model development", Journal of American Water Resources Association, Vol. 34, pp. 73-89. E-ISSN 1752-1688. DOI 10.1111/j.1752-1688.1998.tb05961.x.

[2] Bannari, A., Morin, D., Bonn, F., and Huete, A. (1995) “A review of vegetation indices", Remote Sensing Reviews, Vol. 13, No. 1, pp. 95-120. DOI 10.1080/02757259509532298.

[3] Barane, P. and Dwarakish, G. S. (2017) "Bridging the gap between potential and actual use of satellite data", Plugin Repository [Online]. Available: https:/github.com/PrathamGitHub/ NITK_RS-GIS_17/blob/master/Information.pdf [Accessed: 23 Feb. 2018]

[4] Bastiaanssen, W.G.M., Molden, D.J. and Makin, I.W. (2000) "Remote sensing for irrigated agriculture: Examples from research and possible applications", Agricultural Water Management, Vol. 46, No. 2, pp.137-155. ISSN 0378-3774. DOI 10.1016/S0378-3774(00)00080-9.

[5] Benedetti, R. and Rossini, P. (1993) "On the use of NDVI profiles as a tool for agricultural statistics: The case study of wheat yield estimate and forecast in Emilia Romagna", Remote Sensing of Environment, Vol. 45, No. 3, pp. 311-326. ISSN 0034-4257. DOI 10.1016/0034-4257(93)90113-C.

[6] Brom, J. (2015) "Raster Best Fit Scatterplot for QGIS" [Online]. Available: http://www.jbrom. smoothcollie.eu/ [Accessed: 23 Feb. 2018].

[7] CGIAR-CSI (The CGIAR Consortium for Spatial Information) (2017) [Online]. Available: http://srtm.csi.cgiar.org / [Accessed: 23 Feb. 2018].

[8] Chavez, P. S. (1996) "Image-based atmospheric corrections - revisited and improved", Photogrammetric Engineering and Remote Sensing, Vol. 62, No. 9, pp. 1025-1036.

[9] Congedo, L. (2016) "Semi-Automatic Classification Plugin Documentation". pp.198. [Online]. Available: https://www.researchgate.net/publication/307593091_SemiAutomatic_Classification_Plugin_Documentation_Release_6011. [Accessed: 23 Feb. 2018]. DOI $10.13 \overline{1} 40 /$ RG.2.2.29 $\overline{4} 74.022 \overline{4} 2 / 1$.

[10] Congedo, L. (2017) “Landsat 8 Surface Reflectance: a Comparison of DOS1 Correction and USGS High Level Data Products". [Online]. Available: https://fromgistors.blogspot.com/2015/01/landsat8-surface-reflectance.html?spref=yml [Accessed: 23 Feb. 2018].

[11] Corredor-Llano, X. C. (2017) “Cloud masking”, [Online]. Available: http://plugins.qgis.org/plugins/ CloudMasking/ [Accessed: 23 Feb. 2018].

[12] De Solan, B., Lesergent, A.D., Gouache,. D. and Baret, F. (2012) "Current use and potential of satellite imagery for crop production management" [Online]. Available: www.google.com.ua/l? ursa $=\mathrm{t} \& \mathrm{rct}=\mathrm{j} \& \mathrm{q}=\&$ esrc $=\mathrm{s} \&$ source $=$ web $\& \mathrm{~cd}=1 \& \mathrm{cad}=\mathrm{rja} \&$ uact $=8 \& \mathrm{ved}=0$ ahUKEwjG1NXM367XA hVPPFAKHaSVBz0QFggxMAA\&url=http $\% 3 \mathrm{~A} \% 2 \mathrm{~F} \% 2 \mathrm{Fec}$.europa.eu $\% 2$ FDocsRoom $\% 2 \mathrm{Fdocume}$ nts $\% 2$ F $432 \% 2$ Fattachments $\% 2$ F $1 \% 2$ Ftranslations $\% 2$ Fen $\% 2$ Frenditions $\% 2$ Fnative\&usg=AOvVaw 3QmcBqsid0qerTe-Hfiqs2 [Accessed: 23 Feb. 2018].

[13] Hogg, E. H., Barr, A. G. and Black, T. A. (2013) "A simple soil moisture index for representing multi-year drought impacts on aspen productivity in the western Canadian interior", Agricultural and Forest Meteorology, Vol. 178-179, No. 15, pp. 173-182, ISSN 0168-1923. DOI 10.1016/j.agrformet.2013.04.025.

[14] Huete, A. R. (1988) “A soil-adjusted vegetation index (SAVI)", Remote Sensing of Environment, Vol. 25, No. 3, pp. 259-309. DOI: 10.1016/0034-4257(88)90106-X.

[15] IDB (Index Data Base) (2017) "Simple Ratio 1600/820 Moisture Stress Index (MSI)", [Online]. Available: https://www.indexdatabase.de/db/i.php [Accessed: 23 Feb. 2018].

[16] Iowa State University (2017) “Corn Diagnostic Guide”, [Online]. Available: https://www.aganytime. com/dekalb/tools/Documents/CornDiagnosticGuide.pdf [Accessed: 23 Feb. 2018]. 
[17] Langner, H., Böttger, H. and Schmidt, H. (2016) "Difference Index with Red Threshold", ResearchGate 09, [Online]. Available: https://www.researchgate.net/search.Search. html?type=publication\&query=Difference $\% 20$ Index $\% 20 \mathrm{with} \% 20 \mathrm{Red} \% 20 \mathrm{Threshold}$ [Accessed: 23 Feb. 2018].

[18] Mandanici, E. and Bitelli, G. (2016) "Preliminary Comparison of Imagery for a Combined Use", Remote Sensing., Vol. 8, pp. 1014; [Online]. Available: www.mdpi.com/journal/remotesensing [Accessed: 23 Feb. 2018]. ISSN 2072-4292. DOI 10.3390/rs8121014.

[19] Matsushita, B., Yang, W., Chen, J., Onda,Y. and Qiu, G. (2007) "Sensitivity of the Enhanced Vegetation Index (EVI) and Normalized Difference Vegetation Index (NDVI) to topographic effects: a case study in high-density Cypress forest", Sensors (Basel), Vol. 5, No. 7, pp. 2636-2651. ISSN 1424-8220. DOI 10.3390/s7112636.

[20] Meera Gandhi, G., Parthiban, S., Thummalu, N. and Christy, A. (2015) "NDVI: Vegetation change detection using remote sensing and GIS - A case study of Vellore District", Procedia Computer Science, Vol. 57, pp.1199 - 1210. ISSN 1877-0509. DOI 10.1016/j.procs.2015.07.415.

[21] NASA and USGS (2017) "Landsat". [Online]. Available: http://eoedu.belspo.be/en/satellites/ landsat.htm [Accessed: 23 Feb. 2018]

[22] Panda, S., Ames, D. and Panigrahi, S. (2010) "Application of Vegetation Indices for Agricultural Crop Yield Prediction Using Neural Network Techniques", Remote Sensing, Vol. 2, pp. 673-696. ISSN 2072-4292. DOI 10.3390/rs2030673.

[23] Pandolfo, A., Antunes, P. and Gong, X. (2017) "Using Landsat TM data for soil moisture mapping" [Online]. Available: https://mafiadoc.com/vegetation-mapping-with_59cceec81723ddd52081b506. html [Accessed: 23 Feb. 2018].

[24] Potić, I., Bugarski, M. and Matić-Varenica, J. (2017) "Soil Moisture Determination using Remote Sensing data for the property protection and increase of agriculture production", Paper presented at the "Worldbank conference on land and poverty", The World Bank, Washington DC, March 20-24, 2017.

[25] Rondeaux, G., Steven, M.D. and Baret, F. (1996) "Optimization of Soil-Adjusted Vegetation Indices", Remote Sensing of Environment, Vol. 55, No. 2, pp. 95-107. ISSN 0034-4257. DOI 10.1016/0034-4257(95)00186-7.

[26] Roujean, J.-L. and Breon, F.-M. (1995) "Estimating PAR absorbed by vegetation from bidirectional reflectance measurements", Remote Sensing of Environment, Vol. 51, No. 3, pp. 375-384. ISSN 0034-4257. DOI 10.1016/0034-4257(94)00114-3.

[27] Sánchez, N., González-Zamora, A., Piles, M. and Martínez-Fernández, J. (2016) “A new soil moisture agricultural drought index (SMADI) integrating MODIS and SMOS products: a case of study over the Iberian Peninsula", Remote Sensing, Vol. 8, No. 4, ISSN 2072-4292. DOI 10.3390/rs8040287.

[28] Sentek Systems website (2015) “Comparisons-between-NDVI", [Online]. Available: http://www. senteksystems.com/2015/11/25/ [Accessed: 23 Feb. 2018]

[29] Tilling, A. K., O'Leary, G. J., Ferwerda, J. G., Jones, S. D., Fitzgerald, G. J., Rodriguez, D. and Belford, R. (2007) "Remote Sensing of nitrogen and water stress in wheat", Field Crops Research, 2007, Vol. 104, No. 1-3, pp. 77-85. ISSN 0378-4290. DOI 10.1016/j.fcr.2007.03.023.

[30] USGS (2017) "Landsat and Agriculture - Case Studies on the Uses and Benefits of Landsat Imagery in Agricultural Monitoring and Production" [Online]. Available: https://pubs.usgs.gov/of/2017/1034/ ofr20171034.pdf [Accessed: 23 May. 2018].

[31] USGS (2017) "Landsat Provides Near Real-Time Global Agricultural Analysis" [Online]. Available: https://landsat.usgs.gov/landsat-global-agricultural-analysis [Accessed: 23 May. 2018].

[32] USGS websites (2017) [Online]. Available: https://landsat.usgs.gov and http://earthexplorer.usgs. gov/ [Accessed: 23 Feb. 2018] 
[33] Wang, L. and Qu, L.L. (2007) "NMDI: A normalized multi-band drought index for monitoring soil and vegetation moisture with satellite remote sensing", Geophysical Research Letters, Vol. 34, No. 20, E-ISSN 1944-8007. DOI 10.1029/2007GL031021.

[34] Wang, Q., Adikua, S., Tenhunena, J. and Granierb, A. (2005) "On the relationship of NDVI with Leaf Area Index in a deciduous forest site”, Remote Sensing of Environment, Vol. 94, No. 2, pp. 244-255. ISSN 0034-4257. DOI 10.1016/j.rse.2004.10.006.

[35] Wang, Q., Blackburn, G. A., Onojeghuo, A. O., Dash, J., Zhou, L., Zhang, Y. and Atkinson, P. M. (2017) "Fusion of Landsat 8 OLI and Sentinel-2 MSI Data", IEEE Transactions on Geoscience and Remote Sensing, Vol. 55, issue 7. ISSN 0196-2892. DOI 10.1109/TGRS.2017.2683444.

[36] Weather Online [Online]. Available: https://www.weatheronline.co.uk/reports/climate/Ukraine.htm [Accessed: 23 Feb. 2018] 